\title{
O uso da ferramenta canvas na construção de projetos de pesquisa
}

The use of a canvas tool in modelling research projects

Maria Bernadeth Ferraz Koteski, Mestre em Literatura, Faculdade de Tecnologia Senai Curitiba, maria.koteski@pr.senai.br.

Daniele M. Lugli, Especialista em Artes Visuais, Faculdade de Tecnologia Senai Curitiba, daniele.lugli@pr.senai.br.

\section{Resumo}

O artigo relata a aplicação do canvas adaptado para a cocriação de projetos de pesquisa direcionado ao TCC. A atividade foi aplicada aos discentes de Design de Moda da Faculdade de Tecnologia SENAI Curitiba resultou em pré-projetos com características distintas aos da turma anterior, que não usou o método.

Palavras-chave: projeto de pesquisa, canvas, colaboração.

\section{Abstract}

This paper describes the use of an adapted business model canvas structure for cocreating undergraduate research projects. The activity was performed with Fashion Design students at the SENAI Technology School in Curitiba and resulted in projects with different features compared to the previous class, which did not use this method.

Keywords: research project; canvas; collaboration. 


\section{SILID IV SIMAR}

\section{Metodologia Senai}

Para Delors (2010) a educação do século XXI deve possibilitar que todos frutifiquem seu talento e criatividade, com capacidade de assumir suas responsabilidades e de desenvolver seu projeto pessoal.

Alinhada com esse pensamento, a metodologia adotada pelo Senai tem seus fundamentos e princípios em estudiosos que adotam a ideia de que o ensino e aprendizagem devem possibilitar não apenas a construção de novos conhecimentos, mas também o desenvolvimento de capacidades. (SENAI, 2013).

Sendo assim, ao se pensar em princípios de uma educação de qualidade, a prática docente deve ter como premissa inicial a teoria de Vygotsky (2007), cujo foco é a ideia de que a interação social, o compartilhamento de ideias entre os indivíduos é que constitui o homem.

Outra contribuição adotada é a de que a educação deve ser desafiadora para o aluno, que deve ter uma postura ativa frente às situações de aprendizagem e passar pelo processo de assimilação, acomodação e equilibração. (PIAGET, 2011).

Ausubel (1980) dá sua contribuição para a metodologia dessa Instituição de Ensino Superior ao apresentar o docente como alguém que deve promover uma aprendizagem significativa. Ele atingirá esse objetivo quando, ao aproveitar os conhecimentos prévios dos alunos e auxiliá-los para a integração dos novos, possibilitando o crescimento intelectual.

Perrrenoud (2000), por sua vez, apresenta a educação baseada em competências, privilegiando um processo de ensino e aprendizagem centrado no aluno. Este deve, a partir de situações desafiadoras, desenvolver suas competências e ser capaz de relacionar os conhecimentos adquiridos com o seu contexto. Ao professor cabe o papel de mediador de aprendizagem, incentivando o aluno a ser autônomo, crítico e reflexivo.

Nesse aspecto, a metodologia também lança mão dos pressupostos da teoria da aprendizagem mediada, que foi elaborada pelo professor e psicólogo judeuisraelense Reuven Feuerstein. Esse método para o desenvolvimento da cognição parte do pressuposto de que relações interpessoais ricas e significativas elevam a capacidade de aprendizagem. (SENAI, 2012)

No que diz respeito a alunos que estudam nos cursos da Faculdade de Tecnologia Senai Curitiba desenvolver capacidades proativas faz-se mais do que necessário, visto que a Instituição adota, em sua prática pedagógica a Pedagogia de Competências (SENAI, 2013) que pressupõe:

a) metodologias ativas centradas em quem aprende, a partir de ações desencadeadas por desafios, problemas e projetos, visando um melhor preparo para o mundo contemporâneo e futuro;

b) formação de alunos autônomos, com iniciativa, proativos, capazes de solucionar problemas, alcançar a metacognição, realizar a 


\section{V SILID IV SIMAR

autoavaliação e, por consequência, conduzir sua autoformação e aperfeiçoamento.

Para atingir tais resultados estão previstas no planejamento pedagógico as situações de aprendizagem, entendidas como atividades desafiadoras, mas ainda possíveis de serem realizadas pelo estudante naquele momento do aprendizado. Essas atividades devem apresentar características problematizadoras e etapas contextualizadas que possibilitem ao docente circular o máximo de informações e explorar diferentes estratégias de ensino, sempre considerando a motivação do discente.

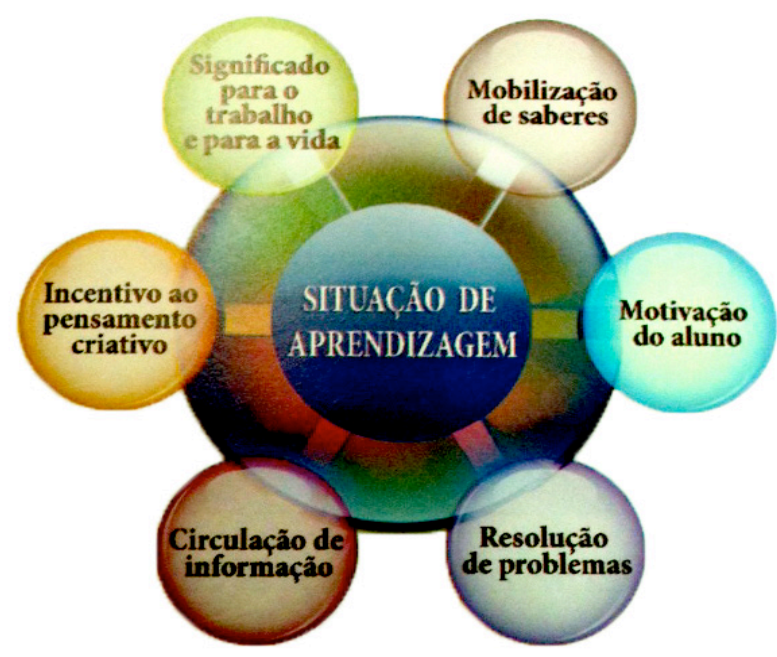

Figura 1: Atributos de uma situação de aprendizagem alinhada à metodologia. Fonte: SENAI (2012)

A partir dessas premissas, todos os cursos oferecidos devem prever o papel do docente como mediador, ou seja, aquele que procura assegurar que o processo de aprendizagem seja efetivo, monitorando a receptividade e a reciprocidade do aprendiz, a efetividade do estímulo, a mediação oferecida e a favorabilidade do ambiente.

\section{O projeto como estratégia de ensino}

A elaboração de projetos de pesquisa, atividade inerente ao desenvolvimento de futuros Trabalhos de Conclusão de Curso (TCCS), geralmente se apresenta como uma atividade que traz muitas dificuldades ao acadêmico, devido a pouca familiaridade com atividades de pesquisa com maior rigor científico.

Para Cervo et al. (2007) o papel de um projeto de pesquisa é garantir a viabilidade de uma pesquisa, fazendo a previsão e a provisão necessária para se atingir todas as etapas previstas nele. Ele deve ser planejado de forma rigorosa, a fim de que o autor não se perca, futuramente, no emaranhado de dados colhidos, sem saber como organizá-los. (LAKATOS; MARCONI, 2010). 
Gil (2010), por sua vez, afirma que para uma pesquisa ter êxito é necessário que o pesquisador apresente capacidades como: (a) conhecimento do assunto; (b) curiosidade; (c) criatividade; (d) integridade intelectual; (e) atitude autocorretiva; (f) sensibilidade; (g) disciplina na imaginação; $(h)$ perseverança e paciência; e (i) confiança.

Essas capacidades devem ser desenvolvidas por cada docente e pelas metodologias de ensino adotadas tanto pela Instituição e, por extensão, pelos docentes.

Para que essa metodologia seja efetivada na prática, adotam-se diferentes estratégias e ferramentas. Foi o caso da atividade que seu resultou no presente estudo, que partiu da aplicação do canvas, geralmente adotado para criação de modelos de negócios, para a cocriação do projeto de pesquisa na turma do $5^{\circ}$ período.

Nessa fase do Curso de Tecnologia em Design de Moda da Faculdade de Tecnologia Senai Curitiba, na disciplina de Projeto Integrador, os alunos, como atividade obrigatória e prevista no regulamento do Trabalho de Conclusão de Curso (TCC), devem elaborar seu pré-projeto de pesquisa. Ao final desse período, o aluno defende seu estudo inicial em uma banca e, após a devida colaboração de outros docentes, o pré-projeto é ajustado, se isso se fizer necessário. Transforma-se, assim, no projeto de pesquisa que será desenvolvido no $6^{\circ}$ período e consolidado no TCC. No caso específico dessa Instituição de Ensino Superior ele pode ser apresentado em forma de monografia (teórica ou com apresentação de produto), projeto de coleção ou plano de negócio.

Para efeitos de organização dos tópicos do pré-projeto e projeto de pesquisa a ser desenvolvido, adaptou-se a estrutura prevista por Marconi e Lakatos (2010), conforme sequência apresentada no Quadro 1. 


\section{SILID IV SIMAR}

\section{IDENTIFICAÇÃO DO AUTOR \\ 2 EIXO \\ 3 TEMA \\ 4 DELIMITAÇÃO DO TEMA \\ 5 TÍTULO PROVISÓRIO \\ 6 JUSTIFICATIVA \\ 7 PROBLEMATIZAÇÃO \\ 8 METODOLOGIA \\ 9 OBJETIVOS \\ 9.1 OBJETIVO GERAL \\ 9.2 OBJETIVOS ESPECÍFICOS \\ 10 REVISÃO DE LITERATURA \\ 11 REFERÊNCIAS \\ 12 REFERÊNCIAS COMPLEMENTARES}

Quadro 1- Elementos do projeto de pesquisa. Fonte: Adaptado de Marconi e Lakatos (2010)

Ao se elaborar uma pesquisa, segundo as referidas autoras, pretende-se não fazer tudo ao acaso, daí a necessidade de se adotar uma estrutura que dê conta do processo. Gil (2010), por sua vez, afirma que embora alguns estudiosos pensem que $o$ a elaboração de um projeto possa tornar o processo mais mecânico e menos criativo, na verdade ele colabora para que se esquematizem os tipos de atividade e experiências criativas.

Dessa forma, ao se adotar essa estrutura "fechada" para os projetos de pesquisa no curso de Design de Moda, espera-se que os alunos sejam capazes de sistematizar seu pensamento e, a partir dessa organização, possam desenvolver estudos relevantes, criativos e inovadores para a área.

\section{O processo colaborativo}

Segundo Heemann et al (2008), o termo colaboração designa uma atuação conjunta, na qual ocorre o auxílio entre pessoas com objetivo de se alcançar um determinado fim.

É um conceito amplo, que pode ser aplicado em diversos contextos e se desenvolver em diferentes níveis, e vem sendo utilizado de maneira crescente, principalmente relacionado a abordagens inovadoras nas áreas de design, negócios, pedagogia, entre outras. Os autores atribuem tal fenômeno ao processo de globalização, que leva pessoas que vivem em contextos diferentes a trabalhar de 
forma conjunta. Dessa forma, a colaboração pode ser considerada uma condição fundamental do desenvolvimento na sociedade contemporânea.

Acredita-se que uma equipe é capaz de atingir melhores resultados do que uma pessoa trabalhando individualmente. Isso ocorre porque cada indivíduo possui habilidades e conhecimentos distintos, e essa diversidade de opiniões possibilita a abordagem de um problema sob diferentes perspectivas, resultando numa avaliação mais completa do mesmo (VIVACQUA; GARCIA, 2012).

Castro e Menezes (2012) ainda afirmam que se aprende muito na interação com o outro ao resolver problemas de forma conjunta, explicar e debater ideias e críticas e construir sínteses de maneira coletiva. Isso quer dizer que o trabalho colaborativo envolve níveis de cognição mais elaborados, o que o torna um fator de grande impacto na construção do conhecimento.

$\mathrm{Na}$ metodologia adotada pela Faculdade de Tecnologia Senai Curitiba, o professor deve sempre atuar como mediador e propor situações para compartilhamento de ideias e trabalho colaborativo. Ele deve prever, no desenvolvimento de suas aulas, atividades que: (a) encorajem os alunos a se ajudarem e ouvirem uns aos outros; (b) promovam oportunidades para trabalhos em grupo; (c) possibilitem métodos de ensino em grupo e encorajem os alunos a compartilhar suas experiências com outros. (SENAI, 2012).

Dessa forma, a aplicação de ferramentas colaborativas para o desenvolvimento do projeto de pesquisa, além de possibilitar uma melhoria individual, atende aos pressupostos da metodologia adotada pela Instituição.

\section{A ferramenta canvas}

O canvas, ou quadro de modelo de negócios, é uma ferramenta concebida por Osterwalder (2011) para facilitar o desenvolvimento de um modelo de negócios de maneira coletiva. Ele consiste num quadro seccionado em nove partes, e cada uma delas diz respeito a um componente essencial da estrutura do modelo de negócios.

O objetivo é preenchê-lo, por meio de anotações breves em post-its, de forma que todos os participantes contribuam com ideias para a definição desses componentes. Os post-its são um elemento importante nesse tipo de atividade, pois permitem o reposicionamento das ideias conforme surjam novas contribuições e esclarecimentos. 


\section{SILID IV SIMAR \\ PUC-Rio - Dias 28, 29 e 30 de julho de 2015}

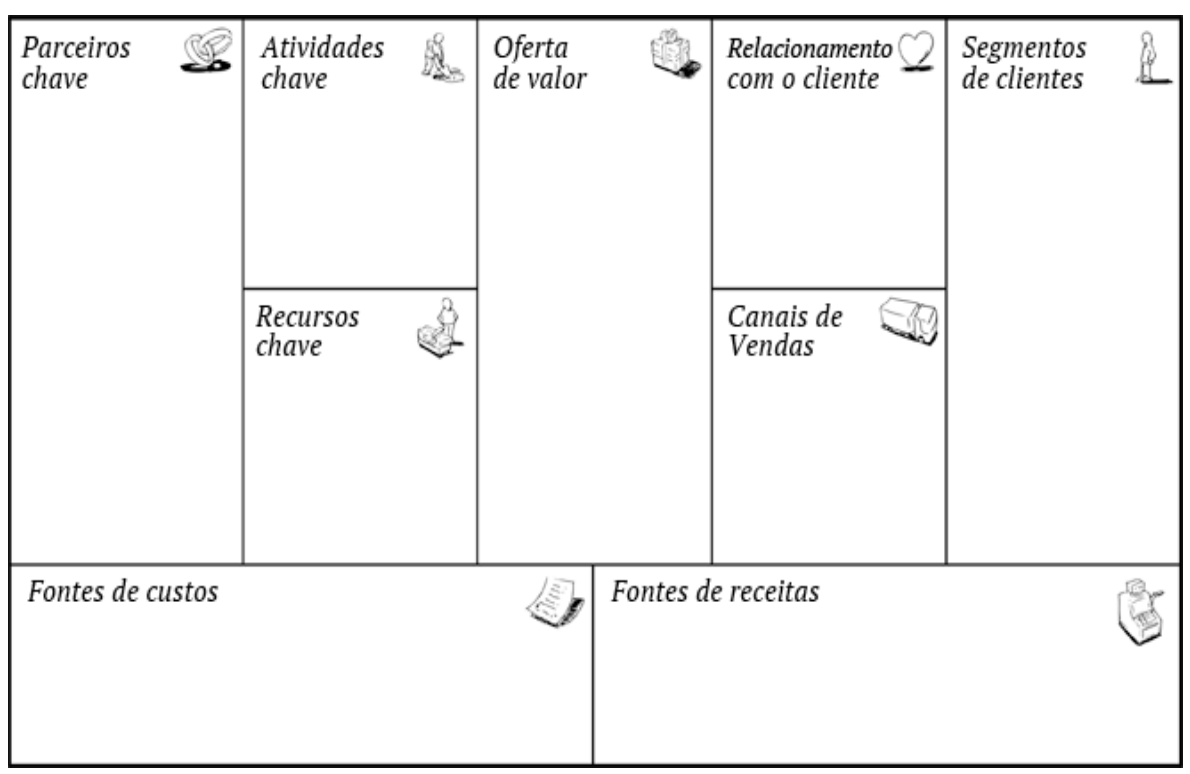

Figura 2: Estrutura do canvas. Fonte: Osterwalder (2011)

Ainda segundo o autor, a ferramenta promove entendimento, discussão, criatividade e análise, pois trabalha com uma linguagem imagética e dinâmica. Dessa forma, torna-se um instrumento relevante para processos de cocriação que envolvam a concepção de novas ideias.

Para Carrasco (2013), a vantagem da utilização do modelo Canvas é a sua simplicidade, pois que ele deverá ser apresentado, de modo simples (apenas uma folha), em um processo chamado de "pivô", uma vez que possibilita que sejam acrescentadas ideias e sugestões, permitindo críticas e modificações.

Percebeu-se essa situação no desenvolvimento da atividade em sala, que se encontra descrita a seguir.

\section{O canvas adaptado}

Considerando-se os benefícios da ferramenta canvas em processos de cocriação de novas ideias, observou-se a possibilidade de se utilizar esse formato na geração de um modelo de projeto de pesquisa.

Partindo da estrutura do canvas original, os componentes do modelo de negócio foram substituídos pelos componentes do projeto de pesquisa já descritos anteriormente, resultando no quadro apresentado na Figura 2. 

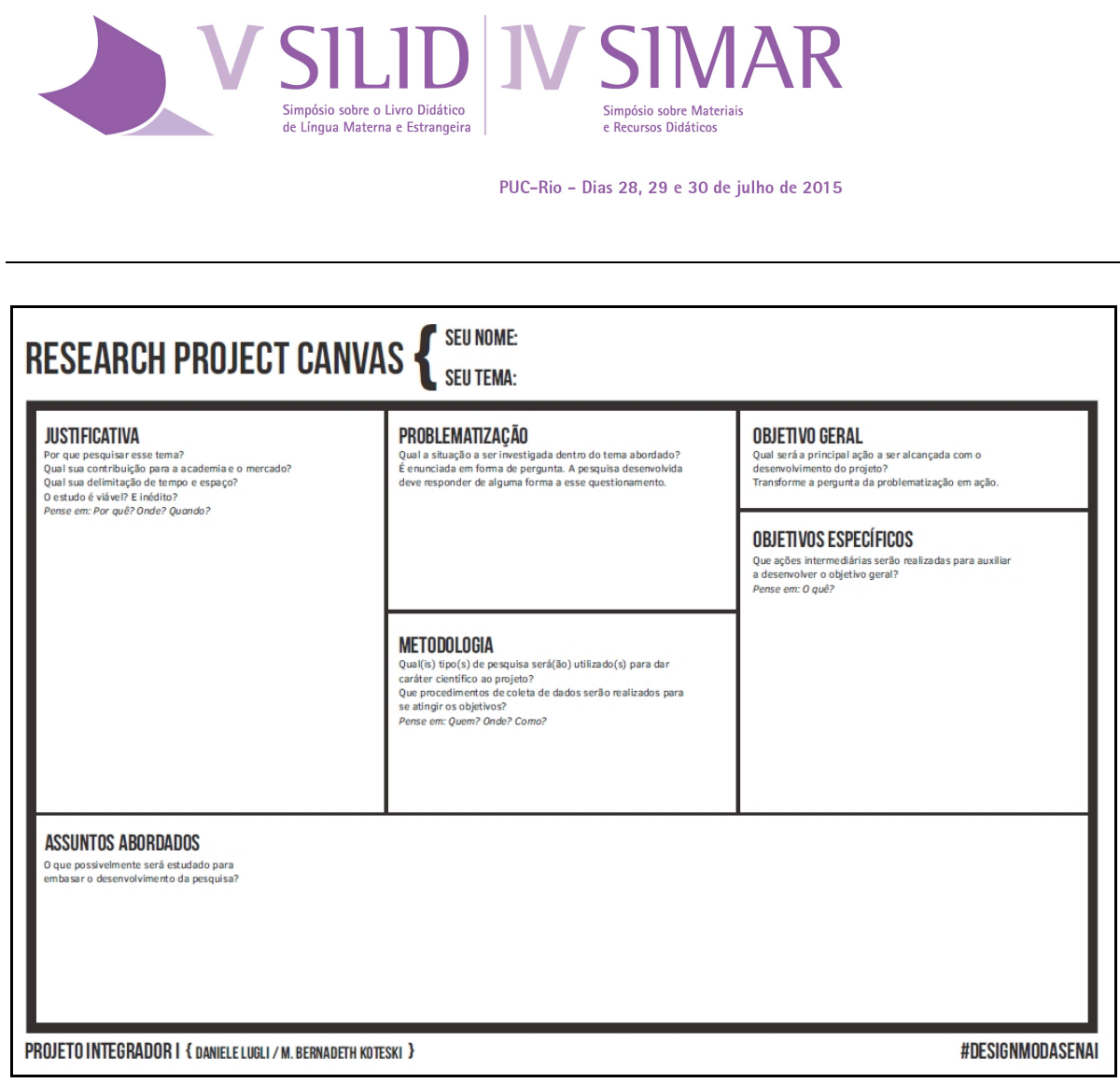

Figura 3: Canvas adaptado. Fonte: As autoras (2015)

Junto aos campos correspondentes aos tópicos do projeto foram inseridas perguntas visando estimular a melhor compreensão dos itens e o questionamento direcionado da ideia inicial:

a) Justificativa: por que pesquisar esse tema? Qual sua contribuição para a academia e o mercado? Qual sua delimitação de tempo e espaço? 0 estudo é viável? E inédito? Pense em: "Por quê?", "Onde?", "Quando?".

b) Problematização: qual a situação a ser investigada dentro do tema abordado? É enunciada em forma de pergunta. A pesquisa desenvolvida deve responder de alguma forma a esse questionamento.

c) Objetivo geral: qual será a principal ação a ser alcançada com o desenvolvimento do projeto? Transforme a pergunta da problematização em ação.

d) Objetivos específicos: que ações intermediárias serão realizadas para auxiliar a desenvolver o objetivo geral? Pense em: "O quê?"

e) Metodologia: qual(is) tipo(s) de pesquisa será(ão) utilizado(s) para dar caráter científico ao projeto? Que procedimentos de coleta de dados serão realizados para se atingir os objetivos? Pense em: "Quem?", "Onde?", "Como?".

f) Assuntos abordados: o que possivelmente será estudado para embasar o desenvolvimento da pesquisa? 
Como pode se perceber, os tópicos do projeto apresentados no Quadro 1 foram adaptados para o canvas. Isso demonstra a versatilidade do modelo, que pode ser utilizado em diferentes situações/conteúdos de sala de aula, dependendo do que se quer criar de forma colaborativa.

\section{Desenvolvimento da atividade}

A atividade foi realizada em sala de aula, durante o horário da disciplina Projeto Integrador. Ao longo das semanas anteriores, os discentes receberam informações gerais sobre o trabalho de conclusão de curso, sua estrutura, métodos e possibilidades. Também foram orientados a mapear ideias de temas para desenvolver em suas pesquisas, e já procurar informações e referências sobre o assunto.

Os estudantes foram reunidos em equipes de três pessoas, de acordo com a grande área de interesse. Optou-se por esse agrupamento para que os colegas já tivessem algum repertório que pudesse contribuir no processo de geração de ideias. Cada um recebeu seu canvas adaptado impresso em formato $A 3$, um bloco de postits e uma caneta.

Cada participante deveria explicar brevemente sua ideia ou tema para contextualizar os demais colegas. A partir de então, reservaram-se 15 minutos para que todos se dedicassem ao preenchimento do canvas daquele objeto de estudo específico. Os estudantes foram orientados a gerar o maior número possível de ideias, sem passar ainda por nenhum tipo de filtro ou julgamento.

Passados os 15 minutos, o processo foi reiniciado a partir da ideia de outro colega, e o segundo canvas foi preenchido com a colaboração dos três participantes. Finalmente, foi realizado o terceiro ciclo, repetindo o mesmo procedimento.

Finalizada a atividade em sala, os painéis foram recolhidos e levados à sala dos professores, onde foram dispostos em murais. Foram disponibilizados post-its de cores diferenciadas para que, durante a semana, os professores pudessem ler as ideias geradas e dar suas próprias sugestões. Todos os professores foram convidados a contribuir, independentemente do tema do trabalho estar contido em sua área de atuação.

$\mathrm{Na}$ aula seguinte, uma semana após a realização da atividade, os canvases foram devolvidos aos discentes. A partir desse modelo, cocriado por colegas e professores, eles deveriam refletir sobre as contribuições e, finalmente, construir o pré-projeto no formato acadêmico. Apenas nesse momento as ideias foram filtradas em relação à sua pertinência e viabilidade de estudo, e alinhadas às expectativas e desejos do discente. 


\section{Avaliação dos resultados}

Concluiu-se, em discussão entre os professores orientadores e da disciplina, que os pré-projetos gerados após essa atividade estavam mais criativos em suas propostas e coerentes em sua estrutura se comparados aos entregues pela turma anterior, que trabalhou de maneira tradicional e individual.

Acredita-se que o caráter dinâmico da atividade despertou maior interesse pelo desenvolvimento do assunto e facilitou a criatividade no pensamento. A linguagem sucinta e visual do canvas, mais próxima à trabalhada no cotidiano dos alunos de design, tornou a atividade científica mais palpável e acessível.

Outro aspecto levantado é que participação de outros discentes e, principalmente, dos docentes deu maior segurança ao estudante na escolha de seu tema de pesquisa, que já haveria passado por essa "validação" prévia. Além disso, a exposição da ideia ao outro trouxe a necessidade de que as relações entre problemática e objetivos ficassem mais claras e coerentes.

Dessa forma, tornou-se obrigatória uma clareza inicial antes da atividade em grupo, levando os alunos a refletirem com maior profundidade sobre sua temática.

\section{Considerações finais}

A partir da interação entre os alunos, o processo de elaboração do pré-projeto pode se tornar mais prazeroso e com resultados mais efetivos e afetivos, pois cada um se corresponsabilizou pelo outro. Isso ocorreu porque a atividade desenvolvida, além de possibilitar a melhoria dos pré-projetos, permitiu a integração dos que tinham interesses afins.

Portanto, os resultados demonstraram que ferramentas de áreas diferentes da educação, mas que possibilitem o compartilhamento de ideias, podem ser adaptadas e aplicadas com sucesso em sala de aula. Além disso, o aluno pode vislumbrar uma aplicabilidade diferente para o canvas e abre a perspectiva de que, na futura vida profissional, ele possa utilizá-lo em outras situações de trabalho colaborativo.

\section{Referências Bibliográficas}

AUSUBEL, D. P.; NOVAK, J. D.; HANESIAN, H. Psicologia educacional. Tradução Eva Nick. Rio de Janeiro: Interamericana, 1980.

CARRASCO, L. C. et al. Uma análise da aplicação do Business Model Canvas - BMC a partir da visão de empreendedores que se encontram em diferentes fases do negócio - uma experiência da incubadora de empresas e projetos do Inatel. XXIX Seminário Nacional de Parques Tecnológicos e Incubadoras 


\section{V SILID IV SIMAR

de Empresas, Belém, PA, Brasil. Disponível em http://www.anprotec.org.br/Relata/ArtigosCompletos/ID\%20164.pdf. Acesso em 05 ago. 2015.

CASTRO, A.; MENEZES, C. Aprendizagem colaborativa com suporte computacional. In: PIMENTEL, M.; FUKS, H. Sistemas colaborativos. Rio de Janeiro: Elsevier, 2012. p. $135-153$.

CERVO, A. L.; BERVIAN, P. A. Metodologia científica. 6. ed. São Paulo: Pearson, 2007.

DELORS, J. A educação ou a utopia necessária. In: Educação: um tesouro a descobrir - Relatório para a Unesco da Comissão Internacional sobre educação para o século XXI. Brasília, 2010. Disponível em http://unesdoc.unesco.org/images/0010/001095/109590por.pdf. Acesso em 07 ago. 2015.

GIL, A. C. Como elaborar projetos de pesquisa. 5. ed. São Paulo: Atlas, 2010.

HEEMANN, A.; LIMA, P.; CORRÊA, J. Fundamentos para o alcance da colaboração em design. Anais do $\mathbf{8}^{\circ}$ Congresso Brasileiro de Pesquisa e Desenvolvimento em Design. 2008.

LAKATOS, E. M. \& MARCONI, M. de A. Fundamentos de metodologia científica. 7. ed. São Paulo: Atlas, 2010.

PERRENOUD, P. Dez novas competências para ensinar. Porto Alegre: Artmed, 2000.

PIAGET , J. Seis estudos de psicologia. 25. ed. Rio de Janeiro: Forense Universtária, 2011.

SENAI. Metodologia Senai de formação profissional com base em competências: capacitação de mediadores. Curitiba, 2012. (Apostila de Treinamento)

SENAI. Departamento Nacional. Metodologia Senai de Educação Profissional. Brasília: Editora Aquarella, 2013.

OSTERWALDER, A. Business ModelGeneration - inovação em modelos de negócios: um manual para visionários, inovadores e revolucionários. Rio de Janeiro: Alta Books, 2011. 
VIVACQUA, A. S.; GARCIA, A. C. B. Ontologia de colaboração. In: PIMENTEL, M.; FUKS, H. Sistemas colaborativos. Rio de Janeiro: Elsevier, 2012. p. 34-49.

VYGOTSKY. L. S. Formação social da mente. São Paulo: Martins Fontes, 2007. 